\title{
FUNÇÃO SOCIAL/SOLIDÁRIA DA EMPRESA NOS NEGÓCIOS VIRTUAIS
}

\author{
Gleissa Mendonça Faria Cardoso \\ Advogada, Graduada em Direito pelo ILES/ Ulbra em \\ Itumbiara/GO, Especialista em Direito de Família pela \\ Universidade Cândido Mendes, Mestranda em Direito pela \\ UNIMAR em Marília/ São Paulo. Técnica em Enfermagem \\ pelo Colégio Sena Aires em Itumbiara/GO, Especialização \\ profissional de nível técnico em Enfermagem do Trabalho \\ pelo Projeção-Central de Ensino do Triângulo em \\ Uberlândia/MG. \\ E-mail: gleissafaria@yahoo.com.br

\section{Valter Moura do Carmo} \\ Doutor em Direito pela Universidade Federal de Santa \\ Catarina (UFSC). Mestre em Direito pela Universidade de \\ Fortaleza (Unifor). Professor do Programa de Pós- \\ Graduação em Direito da Universidade de Marília \\ (UNIMAR), em estágio pós-doutoral. \\ E-mail: vmcarmo86@gmail.com
}

RESUMO: Em virtude do surgimento das tecnologias e seu surpreendente crescimento, surge o modelo de comércio eletrônico, com a finalidade de atender esse exigente consumidor contemporâneo. Contudo, a estrutura virtual da empresa não a exime de cumprir sua função social/ solidária. A propriedade deve atender aos interesses sociais, o reconhecimento da função social da propriedade implica em condutas por parte da empresa, que não só tem a obrigação de não exercer seu direito em prejuízo de outro, como, também, tem a obrigação de exercê-lo em favor da coletividade. A função social/solidária visa compatibilizar os interesses individuais aos interesses coletivos, sob a ótica de assegurar uma existência digna e justa para presentes e futuras gerações. Nesse sentido, a pesquisa buscou expor a evolução tecnológica e os empreendimentos virtuais, bem como, pesquisar as vantagens e desvantagens dos negócios virtuais e, por fim, analisa função social/solidária da empresa e seus reflexos nos negócios virtuais. Utilizou-se para tanto o método dedutivo, baseado em fontes doutrinarias, legislação, dissertações e artigos científicos.

Palavras-chave: Empresa; Função social; Internet; Negócios virtuais.

\section{Social /solidary function of the company in virtual business}

ABSTRACT: Due to the emergence of technologies and their surprising growth, the e-commerce model emerges, in order to meet this demanding contemporary consumer. However, the virtual structure of the company does not exempt it from fulfilling its social / solidarity function. Property must meet social interests, recognition of the social function of property implies conduct on the part of the company, which not only has the obligation not to exercise its right to the detriment of another, but also has the obligation to exercise it in favor of collectivity. The social / solidarity function aims at reconciling individual interests with collective interests, with a view to ensuring a dignified and just existence for present and future generations. In this sense, the research sought to expose technological evolution and virtual enterprises, as well as to research the advantages and disadvantages of virtual businesses and, finally, to analyze the company's 
social / solidarity function and its reflexes in virtual businesses. The deductive method was used, based on doctrinal sources, legislation, dissertations and scientific articles.

Keywords: Company; Social role; Internet; Virtual business.

\section{INTRODUÇÃ̃O}

Resultado do processo de globalização mundial, a evolução tecnológica espalha seus efeitos nas mais diversas áreas e setores, notadamente, é um grande e eficiente instrumento no campo empresarial, possibilitando mais celeridade, facilidade, diversidade e rentabilidade nos negócios. A internet se tornou um verdadeiro diferencial no atual mercado competitivo e com ela surge o comércio eletrônico, o "e-commerce".

A empresa tem sua importância no contexto social, visto que ocupa papel relevante nas sociedades capitalistas, uma vez que toda a economia é fruto de processo produtivo de natureza empresarial. Em uma sociedade de consumo pós-moderna, observar-se-á que a promessa de satisfação dos desejos ocorre exclusivamente por meio da aquisição de novos bens ou serviços, é então que nascem os negócios virtuais, justamente para satisfazerem os anseios dos diversos perfis de consumidores.

As estruturas do direito privado passam a ser norteadas pelo paradigma da função social e da solidariedade, como fim a ser alcançado à dignidade da pessoa humana. A função social da empresa determina uma conscientização da atuação do particular, em busca da consonância entre interesse individual e o social, sem, é claro, desviar-se de seu intuito lucrativo, inerente à instituição. O mesmo ocorre em relação a sua função solidária que está voltada ao conceito de justiça distributiva, social, ao aspecto do bem-comum.

A pesquisa tem o escopo de expor a evolução tecnológica e os empreendimentos virtuais, bem como pesquisar as vantagens, desvantagens que envolvem os negócios virtuais e, por fim, analisa função social/solidária da empresa e seus reflexos nos negócios virtuais.

A pesquisa foi baseada em fontes doutrinárias, legislação, dissertações e artigos científicos, tudo com a finalidade de demonstrar como funcionam os negócios na internet e seus desdobramentos, utilizando-se para tanto o método dedutivo.

A fundamentação deste trabalho sustenta-se nas novas tecnologias que fomentam o mercado de uma forma instantânea, impactando diretamente na economia, nas relações de consumo e perante a sociedade, e a importância do cumprimento da função social/solidária nesses negócios firmados no mundo virtual.

\section{A EVOLUÇÃO TECNOLÓGICA E OS EMPREENDIMENTOS VIRTUAIS}

Nas últimas décadas, a influência das tecnologias no cotidiano das pessoas cresceu assustadoramente, tarefas monótonas e que demandavam muito tempo para executá-las agora em questão de segundos são concluídas, atos complexos agora facilitados pela informatização, gerando maior facilidade, celeridade e efetividade na seara social e profissional.

A transição do mundo analógico para o digital foi considerada uma importante evolução para a humanidade, principalmente com a chegada da internet no Brasil por volta dos anos 90, considerada um conglomerado de computadores integrados que possuíam um conjugado de protocolos e serviços em comum. 
A Internet surgiu em 1969 nos Estados Unidos. Interligava originalmente laboratórios de pesquisa, a chamada ARPAnet (ARPA: Advanced Research Projects Agency) que era uma rede do Departamento de Defesa (DoD) norte-americano. A Internet, em 1995, época de sua abertura comercial no Brasil possuía, cerca de 44.000 redes estendidas em 160 países e 26.000 entidades comerciais registradas. Algo entre 40 a 50 milhões de computadores estavam conectados aos hosts da Internet e desenvolvendo numa estimativa de $10 \%$ a $20 \%$ ao mês (MENEZES, 2002).

A tecnologia digital ultrapassa fronteiras, limites territoriais, aproxima pessoas do mundo inteiro, tornou-se uma ferramenta útil e dependente na vida das pessoas, devido a essa amplitude e necessidade, ambientes públicos, como bares, hotéis, restaurantes entre outros, têm acompanhado essa evolução tecnológica, adequando seus ambientes comerciais e culturais a essa nova era, como a implantação de internet via Wi-fi livre.

Após a criação da Internet e com o início dos negócios por meio dela, o número de usuários da Internet aumentou expressivamente. Em outubro de 2017 foi divulgado, pela Conferência das Nações Unidas sobre Comércio e Desenvolvimento, um relatório sobre economia digital, o qual coloca o Brasil em quarto lugar no ranking mundial de usuários de internet, com 120 milhões de pessoas conectadas (RIDOFRANZ, 2017).

Na década de 1990, começou-se a descoberta de determinadas lojas que comercializavam seus produtos de forma inédita, mas nessa época a Internet ainda estava em fase de maturação. No início de 2001, determinadas empresas encontraram dificuldades para obter capital e confiança para esses novos investimentos, preocupadas com o risco de retorno sobre o investimento e com o novo mercado tecnológico (SALVADOR, 2010, p. 6).

"Em um mundo conectado, informatizado e iterativo o ambiente de negócios vem se alterando de forma gradativa" (OLIVEIRA, 2014, p. 68). Inicialmente os negócios na internet se baseavam somente na presença, ou seja, em ter um site na rede. Em uma segunda etapa as empresas passaram a realizar transações, comprar e vender de forma on-line. Hoje, já em uma terceira etapa, o foco está em pensar de maneira sistêmica em como o ambiente da internet pode colaborar com o sucesso da empresa.

É possível perceber que o formato de relacionamento entre as partes (empresa e consumidor) também se modifica. Na primeira fase, a relação pode ser considerada passiva. A empresa coloca uma informação no site e o usuário somente recebe essa informação. Na segunda etapa, a relação passa da simples informação para um processo de escolha e compra de algum produto, pode-se dizer que é uma relação ativa. Hoje em dia, a terceira fase vem edificando uma forma de relação interativa onde as partes envolvidas se interagem para trocar informações, comunicar, realizar transações entre outras ações.

Ainda assim, apesar da consolidação dos negócios na internet entre as pessoas e as empresas esteja ocorrendo ao longo de décadas, desde o nascimento da internet, na atualidade os relacionamentos com os fornecedores e clientes, o gerenciamento de dados e do conhecimento, têm se desenvolvido e disseminado sob a égide da inovação, da interação contínua, da conectividade, da expansão e da globalização, favorecidos pelo ambiente digital.

"Las nuevas tendencias del mercado se orientan hacia una verdadera transformación sobre el concepto de venta de productos y servicios, que apunta a la captura de mayor cantidad de clientes potenciales a través de las más modernas herramientas informáticas” (MARKER, 2017).

A empresa para participar destas novas transformações, mais do que ter acesso à tecnologia da internet, é imprescindível pensar neste novo padrão de forma estratégica e sistêmica. Para cooperar com esta mudança não basta apenas ter um endereço de site na internet, mas é 
preciso ter uma plataforma que integre ferramentas de interação como site, aplicativos, comércio, redes sociais, chats, entre outras (OLIVEIRA, 2014, p. 69).

Muitas empresas tradicionais (físicas) estão aderindo ao mundo virtual, surgindo à figura da empresa mista, um novo ambiente empresarial que está se expandindo, algumas empresas serão capazes de aproveitar as mudanças, encarando-as como oportunidades, já outras as enxergarão como obstáculos e serão, facilmente, colocadas para fora do mercado. Os negócios na Internet habilitam novas atividades de criação de valor, por meio da conexão e intermediação de vários atores no campo dos mercados, que permite a redução dos custos nas transações e a abertura de nichos para as pequenas.

Ultimamente as empresas disputam o mercado no mundo físico e virtual. Neste novo ambiente competitivo, é vital investir na criação de valor no mercado físico e no mercado virtual. Muitas empresas estão trocando ou apoiando seus processos e operações no mundo físico por processos virtuais. No processo virtual, o produto ou serviço existe na forma de dados e informações digitalizadas. Essa informação é disponibilizada e lançada digitalmente. Em virtude das oportunidades para as empresas, possibilitadas pelos avanços tecnológicos, um novo espaço empresarial está se iniciando (PEREIRA; MAIA; SERIO, 2002).

Este novo ambiente de TI (Tecnologia de Informação) faz promessas de novas e revolucionárias oportunidades, e representa grandes riscos para as organizações. A fim de modificar suas bases de competitividade e de estratégia para o futuro, as empresas têm buscado investir amplamente nas tecnologias de informação e comunicação como uma ferramenta poderosa. Dentre elas cita-se o Comércio Eletrônico que, inserido no ambiente digital, permitiu colocar em prática as estratégias das organizações (PEREIRA; MAIA, SERIO, 2002).

Nesse sentido, cita-se aqui o Comércio Eletrônico ou Comércio virtual, venda não presencial ou e-commerce, como um modelo de negócio pela internet, ramificado através de lojas virtuais, que podem ser definidas como um "site de uma única empresa por meio do qual são vendidos produtos ou serviços. Ela pode pertencer ao fabricante (por exemplo, geappliances.com), a um varejista (por exemplo, walmart.com), a pessoas físicas que vendem a partir de suas casas, etc." (TURBAN, 2004, p.37).

O Comércio Eletrônico tem se tornado, a cada dia, mais expressivo e fundamental para a sobrevivência das empresas, tanto prestadoras de serviço como de venda de produtos tangíveis ou não, frente à concorrência. É importante que a empresa adote um modelo de negócios para melhor passar suas informações.

O mercado digital cresce em média $24 \%$ ao ano, mesmo em épocas de crise (ALINE, 2015). Esse novo modelo de mercado cresce, em razão do surgimento das novas e diversas demandas dos atuais consumidores, "Querer é poder. E quando existe demanda, a oferta não demora a aparecer" (BAUMAN, 2007, p. 28). A economia busca satisfazer os mais diversos desejos e exigências, desse atual perfil de cliente volúvel, "O mercado não sobreviveria caso os consumidores se apegassem às coisas. Para sua própria sobrevivência, não pode tolerar clientes comprometidos e leais ou que apenas se mantenham numa trajetória consistente e coesa que resista a desvios" (BAUMAN, 2007, p. 48).

A Internet e seus serviços têm criado um novo espaço para a concretização de negócios. Esse novo ambiente tem fornecido para os agentes econômicos, tanto para as empresas como indivíduos, canais alternativos para trocar informações, comunicar, transferir diferentes tipos de produtos e serviços e começar transações comerciais. 
Por meio do uso de softwares navegadores como o Microsoft Internet Explorer, um usuário pode visualizar páginas em hipertexto estáticas ou dinâmicas, contendo imagens, documentos, som, vídeos e animações, proporcionando assim uma maneira efetiva de comunicação (MENEZES, 2002).

Através do desenvolvimento de websites e das redes sociais, pode-se criar catálogos eletrônicos de produtos, obter informações de clientes sobre os produtos, obter dados sobre as necessidades dos clientes, criar formulários eletrônicos de pedidos de produtos, além de enviar notícias periódicas sobre seus produtos utilizando o e-mail pessoal de cada cliente cadastrado.

A Internet por ser uma rede com infraestrutura predominantemente pública, de fácil, livre acesso e baixo custo, aceita que pequenas empresas possam trocar informações eletrônicas com seus parceiros ou fornecedores utilizando relatórios. Assim, as empresas perceberam que poderiam usar esta infraestrutura de baixo custo para ajudar nos processos de comunicação internos. Cada departamento ou setor dentro da empresa tornava-se cliente ou fornecedor de informações e produtos para outros departamentos, passava-se a ter um comércio eletrônico interno ou privado à organização (MENEZES, 2002).

Um modelo de negócios apresenta o conteúdo, estrutura e governança das transações desenhadas para criação de valor através da exploração de novas oportunidades de negócios. Um modelo de negócios é um método de fazer negócios por meio do qual uma empresa se sustenta, por conseguinte, gerando receita. $\mathrm{O}$ modelo de negócio decifra a maneira como a empresa faz dinheiro, citando onde está posicionada na cadeia de valor (YOSHIDA, 2015).

O Comércio Eletrônico, modelo citado acima, "favorece novas formas de obtenção de ganhos de competitividade nos negócios, interferindo na cadeia de valor adicionado a produtos e serviços dirigidos ao consumidor ou em transações entre empresas". A visão do Comércio Eletrônico, como qualquer tipo de apoio de transações comerciais por meio do uso de infraestrutura digital, tem o benefício de englobar uma gama variada de utilizações da Web para beneficiar ou impulsionar transações comerciais (DINIZ, 1999).

Assim, o comércio eletrônico pode trabalhar como instrumento de promoção (pré-venda), como novo canal de vendas de fato ou de atendimento ao cliente (pós-venda). Pode gerar economia na realização de transações e redução do ciclo de desenvolvimento dos produtos. A sua implementação deve gerar um aprendizado organizacional e tecnológico indispensável para a sua aplicação efetiva. Além disso, acredita-se que o comércio eletrônico ainda propicia o desenvolvimento de novos produtos e de novos modelos de negócio (DINIZ, 1999).

Os avanços tecnológicos acarretam a expansão e popularização de aparelhos eletrônicos, possibilitando ao setor empresarial expandir seus negócios através do meio virtual, de maneira a atingir os mais variados perfis de consumidores, de forma mais eficiente e rápida para suprir as suas necessidades, expectativas e desejos.

A empresa é uma instituição dotada de poder, sua atuação traz impactos para além da ordem econômica, pois reflete também na esfera social, ambiental e política. Especificadamente os negócios virtuais acarretam impactos positivos e negativos às empresas e aos consumidores dessa nova era tecnológica.

\section{VANTAGENS E DESVANTAGENS DOS NEGÓCIOS VIRTUAIS}

Atualmente, a tecnologia veio agregar facilidades e funcionalidades ao mundo contemporâneo, possibilitando que os negócios no meio virtual, antes restrito às barreiras físicas, fossem 
direcionados para o modelo virtual da internet, em que é grande a multiplicidade de ideias, a diversidade de experiências, inclusive ampliando a realidade para além das fronteiras nacionais, permitindo o intercâmbio com culturas e idiomas completamente diferentes. Nesse sentido, as empresas precisam direcionar os seus esforços e se adequarem à nova realidade, conservando-se focadas nas mudanças promovidas pela sociedade, que agora se estende para o fim virtual.

A visão conservadora de mercado aos poucos foi se dissolvendo pelo vasto cartel de oportunidades que o novo mecanismo de vendas proporcionava tanto para os clientes quanto para os investidores. Como atrativo para compras on-line, as empresas investiram em preços competitivos e na possibilidade de parcelar em várias vezes os produtos comprados, aumentando a importância dos negócios no meio virtual.

"Os negócios na internet têm algumas vantagens e também desvantagens (ou limitações) em relação aos negócios convencionais" (COSTA, 2010). Tem-se como vantagem básica a comodidade, quebra dos obstáculos de tempo e distância das transações de compra e venda. A personalização do sistema de acordo com as necessidades do cliente, formas de pagamento diferenciadas, perfis de consumo que tem como resultado um aperfeiçoamento do atendimento às diferentes características de clientes, preços competitivos pelos consumidores e ainda diminuição de custos operacionais (estocagem e funcionários) para as empresas.

O rompimento dos obstáculos do tempo e distância acontece porque, para realizar uma compra através da internet, o consumidor precisa apenas de um computador, notebook, tablet, smartphone, iphone ou outros dispositivos conectados na rede, não tem a necessidade de ir até a loja física, bem como existe a possibilidade de fazer compras de produtos disponíveis para venda em outro país.

A customização dos sistemas às precisões do cliente e os variados perfis de consumo estão conexos, são alternativas de recomendar aos consumidores sobre algo pertinente ao que eles têm habitualidade de comprar, isso é possível ser realizado por meio de inteligência artificial e registros anteriores de compras e acesso aos sites, promovendo assim um melhor atendimento.

As vantagens dos negócios no meio virtual retornam tanto para o cliente quanto para os empreendedores, isso acontece porque as vantagens para os clientes são em razão da própria natureza do negócio na internet, por exemplo, a necessidade social de comunicação, fácil acesso e maior alcance das informações disponibilizadas pela internet. Os benefícios para os fornecedores relacionam-se às novas chances de ampliação dos mercados e maior alcance do público alvo.

Por meio dos negócios na internet os clientes se tornaram donos de suas próprias informações, a oferta ao consumidor se torna mais atrativa e inteligente, pois está presente onde o cliente gosta de se divertir, em seu local de trabalho, onde ele estiver, acrescentando benefício e praticidade, deixando-o à vontade para prestar atenção ou não no conteúdo. Ele pode comparar, refletir, tirar dúvidas e em alguns cliques realizar uma compra sossegado, sem a sensação de invasão de sua privacidade (NETO, 2009).

As vantagens aos consumidores são inúmeras, notadamente na economia de tempo, praticidade, comodidade, formas de pagamentos diferenciadas e acessíveis, facilidade de comparar produtos, preços e marcas, opção de ter um amplo e variado catálogo de produtos e serviços, conforto e tranquilidade para fazer compras onde, quando e como quiser, não tendo que enfrentar filas ou lidar com vendedores inconvenientes.

Para determinadas empresas, os benefícios da participação ativa de uma marca nas redes sociais são vários, tais como: expor a marca em um ambiente digital com grande audiência, en- 
tender hábitos e atitudes dos seus consumidores, relacionar-se com seu público, adiantar tendências de mercado e gerar aumento das vendas. Dentre outras vantagens para as empresas, podemos citar, ainda, o estoque baixo, estrutura de funcionário enxuta, vitrine virtual exposta 24 horas e 365 dias ao ano na rede, marketing virtual eficiente e mais barato, despesas diárias menores, entre outras.

É muito importante que os gestores estejam informados dos novos rumos que o mercado global está tomando, fazendo parte deste fenômeno, as empresas têm muito mais oportunidades de continuarem em postos de ênfase, competindo em um mercado dinâmico e lucrativo.

Mas como nem tudo são vantagens, adiante serão analisados os obstáculos e problemas dos negócios na internet. Os impactos negativos dos negócios virtuais estão ligados a desvios da função social da empresa.

As lojas virtuais não diferem muito das lojas físicas quando se focaliza no consumidor. Esse sempre espera ser bem atendido e encontrar o que anseia, seja onde estiver. Assim sendo, as lojas virtuais precisam ter sistemas objetivos e céleres para que a compra seja completada com sucesso. O consumidor, embora não seja atendido por pessoas, vai interagir com o sistema de compras que também deve levá-lo a finalizar a transação da maneira mais agradável, breve e fácil possível.

Nesse novo campo comercial, nem tudo são benefícios, as lojas virtuais têm algumas desvantagens, dentre elas, estão problemas logísticos, referentes a falhas no prazo de entrega ou entrega de produtos defeituosos, devido à falta de cuidado no manuseio do material, embalagens inadequadas ou no mau gerenciamento no transporte, o que acaba provocando perdas e transtornos aos clientes.

Existem outros problemas entre empresa e consumidor, a título de exemplo, o cliente paga, mas o fornecedor não entrega; o cliente efetua o pagamento, mas o fornecedor entrega mercadoria errada, danificada ou sem qualidade; ou ainda, o fornecedor entrega, mas o cliente se nega a pagar.

A liberdade na internet também traz desvantagem para a empresa e uma vantagem para o consumidor, referente ao encorajamento do consumidor de expor sua opinião sobre a empresa e seus produtos e serviços ofertados, possibilitando, em caso de não satisfação da compra, ao consumidor denegrir a imagem da empresa com maior visibilidade, esteja ele com a razão ou não. Nesse sentido, é preciso responder ao máximo cada consumidor que entra em contato com a empresa através da internet, pois um retorno eficiente e rápido aos clamores dos clientes desenvolve uma relação de credibilidade, segurança e confiança.

Atualmente, à medida que as empresas se tornam cada vez mais digitais, ou condicionadas dos canais digitais, elas passam a ter de encarar desafios com relação à segurança da informação. Segundo Albertin (2012), os principais pontos fracos na segurança da informação são a monitoração, a identificação da informação, o critério de disponibilização e a política de privacidade. Com relação aos responsáveis pela violação das informações, segundo o autor, 9\% são fornecedores e prestadores de serviço, $35 \%$ são funcionários da própria empresa, $25 \%$ de origem não identificada, já 2\% são concorrentes, 17\% são hackers, e 12\% são outros.

Dentre as desvantagens dos negócios concretizados virtualmente, os problemas referentes à segurança, são considerados dos mais sérios, pois em qualquer compra efetuada através de uma loja virtual faz-se necessária a transmissão de dados financeiros e pessoais dos consumidores, podendo acarretar graves problemas se os sistemas operacionais das empresas não forem projetados e focados na segurança. 
Existem também os custos extras de implementação dos sistemas computacionais que uma loja convencional não teria, nesses custos adentram os gastos com programadores, projetistas, web designers, auditores de segurança, entre outros profissionais necessários para afiançar um serviço à altura dos serviços de vendas convencionais (COSTA, 2010).

A intensa corrente de informações e a usabilidade da internet consente que os clientes apresentem milhares de acessos a negócios virtuais em um simples click no mouse, desse modo, se ele não obtiver êxito rápido em sua procura ou tiver problemas para concluir a sua compra, velozmente ele acessará o concorrente.

Outro grande problema ocasionado pelos negócios virtuais é o endividamento dos consumidores. Conforme aponta pesquisa do SPC BRASIL, " $41 \%$ dos brasileiros que compram por impulso estão inadimplentes", segundo a mesma pesquisa, " $36 \%$ dos consumidores fazem compras para aliviar o estresse" (BRUNO, 2015). Isso ocorre quando "o pensamento e a ação das pessoas forem dominados pela evidência da carência material” (BECK, 2011. p. 24). O meio virtual é muito propício para o endividamento em razão da busca momentânea de prazer emocional e principalmente pela facilidade no acesso aos sites de compras que apresentam irresistíveis promoções, que embora as empresas com estrutura física ofereçam as mesmas condições de ofertas, o fato de ter que se deslocar até elas o cliente acaba por resistir à compra.

Além das desvantagens ao consumidor citadas alhures, pode-se citar, ainda, ataque de vírus, a não autorizada renovação automática de serviços, carência de atendimento personalizado, ou seja, carência de contato humano, comunicação inadequada e confusa, dificuldade na troca de produtos, produto diverso da imagem original do site, entre outros.

Em virtude dos problemas, desencadeados pelo surgimento e surpreendente crescimento dos negócios virtuais, fez-se necessária a adaptação das regras consumeristas de acordo com as peculiaridades da própria natureza do negócio por internet. Fábio Ulhoa Coelho (2006, p.42) leciona que, "a circunstância de a venda ter se realizado num estabelecimento físico ou virtual em nada altera os direitos dos consumidores e os correlatos deveres dos empresários". Nas relações de consumo virtual e suas possíveis lacunas existentes, aplicar-se a, no que couber, o Código de Defesa do Consumidor (Lei 8.078/90), e utilizar-se a, ainda, como suporte, demais legislações específicas de acordo com cada caso concreto.

Aplicação do Código de Defesa do Consumidor nas compras e vendas realizadas pela internet, conforme decisão do Tribunal de Justiça do Distrito Federal.

PROCESSO CIVIL. DIREITO DO CONSUMIDOR. AÇÃO DE INDENIZAÇÃO
POR DANOS MORAIS E MATERIAIS. COMPRA E VENDA REALIZADA
PELA INTERNET. FALHA NA PRESTAÇÃO DE SERVIÇO. NÃO ENTREGA
DO PRODUTO E NEM DEVOLUÇÃO DO DINHEIRO. ENRIQUECIMENTO
ILÍCITO E DESRESPEITO AO CONSUMIDOR. DANO MORAL DEVIDO.
QUANTUM. RAZOABILIDADE E PROPORCIONALIDADE. REDUÇÃO. RE-
CURSO CONHECIDO E PROVIDO. SENTENÇA REFORMADA. 1. Aplica-se ao
caso em tela os comandos da Lei 8.078, de 11 de setembro de 1990 - Código de
Defesa do Consumidor -, artigos $2^{\circ}$ e $3^{\circ}$, uma vez que a autor e o réu enquadram-se,
respectivamente, nos conceitos de consumidor e fornecedor [...].

TJ-DF - ACJ: 20130111154766 DF 0115476-63.2013.8.07.0001, Relator: ARNALDO CORRÊA SILVA, Data de Julgamento: 17/03/2015. Grifo nosso.

E ainda, visando à plena tutela ao consumidor diante das mazelas peculiares do ambiente negocial virtual, passou a exigir uma legislação moderna sobre essa relação de consumo via rede mundial de computadores, então, em 2013 nasce o Decreto $n^{\circ}$. 7.962, que regulamenta o CDC, para dispor a respeito da contratação no comércio eletrônico. 
Essa proteção é importante porque o consumidor é a parte vunerável da relação de consumo conforme esculpido no artigo $4^{\circ}$, I, do CDC, e quando é realizado via Internet essa fragilidade tende a se agravar, pois o poder das informações sobre os produtos e serviços concentra-se somente nas mãos do fornecedor.

É pertinente esclarecer que o comércio virtual ou eletrônico deve se orientar, não apenas as regras de responsabilidade, deveres e direitos, impostas pela legislação consumerista, conforme demonstrado acima, mas também, deve se atentar ao cumprimento da função social/solidária da empresa nos negócios virtuais.

A concorrência pela atenção dos clientes desencadeou uma exploração crescente de tecnologias para elevar a sofisticação nos recursos interativos dos sistemas dos negócios virtuais. Este aprimoramento na qualidade dos sistemas aumenta a complexidade de seu crescimento e manutenção, portanto exigindo maior quantidade de recursos financeiros, o que exige da empresa um maior comprometimento que só se justifica se tiver um retorno com aumento dos lucros, mas sem deixar de se atentar ao cumprimento da sua função social/solidária.

\title{
3 FUNÇÃo SOCIAL/SOLIDÁRIA DA EMPRESA E SEUS REFLEXOS NOS NEGÓCIOS VIRTUAIS
}

O Princípio da Função Social foi redefinido na Constituição Federal de 1988 com o advento do princípio da função social da propriedade, no sentido de ser resguardado o direito de propriedade e o direito da livre iniciativa ${ }^{1}$, contudo, necessita-se o respeito à função social. $\mathrm{O}$ direito de propriedade é arrolado no artigo $5^{\circ}$ XXII da $\mathrm{CF} / 88$ em que "é garantido o direito de propriedade", que engloba todos os bens da empresa, não somente os materiais, mas também os imateriais (aqui se aplicam, por exemplo, os estabelecimentos virtuais). Dessa forma, a empresa sendo virtual ou não, deve cumprir sua função social/solidária para não ter seu direito de propriedade restringido.

A função social da empresa é o corolário de uma ordem econômica que, embora composta por vários princípios, possui o intento comum de garantir a todos uma existência digna, conforme os ditames da justiça social. Daí afirmar-se que a empresa tem responsabilidades perante a sociedade como um todo, ou seja, deverá ser responsável e exercer suas atividades com preocupação com o interesse social (sua finalidade).

Neste sentido, Santiago e Medeiros (2017, p. 111-118), afirmam que:

\begin{abstract}
Na contemporaneidade as empresas não devem ser exclusivamente corporações interessadas tão somente no lucro, mas instituições sociais, e, consequentemente, há uma ligação entre sociedade e empresa, que tem por base o crescimento econômico aliado ao crescimento social. Esses alicerces, quando empregados de modo correto pelas empresas, auxiliam no desenvolvimento humano, alcançando de forma positiva o princípio da dignidade da pessoa humana. [...] Dentro da óptica da função solidária, é possível inferir que as organizações empresariais podem interferir diretamente na sociedade, através de suas habilidades do poderio econômico e político, passando a se ocuparem também pelas dificuldades sociais, ambientais, culturais, com potencialidade para o desenvolvimento de ações passíveis de serem aplicadas para possibilitar uma vida digna para a população na qual está inserida.
\end{abstract}

1 Segundo Rachel Sztajn (2004, p. 60): “A liberdade de operar nos mercados (livre iniciativa) tem que ser garantida por normas para que as relações entre agentes do e no mercado atendam aos interesses da sociedade no sentido que Sunstein considera fazer justiça social em mercados livres" (grifos no original). 
A empresa desempenha um papel essencial, nesse sentido, na qualidade de "combustível da economia do país, não deve ficar limitada ao seu fim primordial que é a busca pelo lucro, mas possuir vetores de atuação voltados às necessidades sociais, conforme sua capacidade, seja no âmbito local, seja em maior abrangência" (PAYÃO; SANTIAGO, 2016, p. 252).

A ideia de função social da empresa decorre da previsão constitucional sobre a função social da propriedade, previsto no art. 170, inc. III. Estendida à empresa, a ideia da função social da empresa é de grande influência prática na transformação do direito empresarial brasileiro. É o princípio norteador da regulação interna e externa dos interesses abarcados pela grande empresa. Seu alcance pode ser sentido em campos tão díspares como direito antitruste, direito do consumidor e direito ambiental (SALOMÃO FILHO, 2003, p. 17).

Lopes $(2006$, p. $123 ; 198)$ afirma que toda a construção acerca da função social do contrato e da propriedade se aplica inteiramente à função social da empresa que se compõe em um aspecto dinâmico do direito de propriedade.

Contudo, o reconhecimento do direito de propriedade só se fará verdadeiro enquanto atender a função social a ele inerente. Haja vista que a propriedade não é um direito isolado, absoluto ou irrestrito, mas uma relação social que tem por função gerar desenvolvimento humano, social, econômico e sustentável, ou seja, assegurar uma existência digna. Mas para isso deverá cumprir simultaneamente os critérios e exigências estabelecidos em lei, conforme amparo Constitucional Brasileiro de 1988, em seu art. 186 caput e incisos. $^{2}$

Nessa ótica, Matias e Mendes (2016, p. 17) expõem que:

\begin{abstract}
Alcança se modernamente, portanto, o entendimento de que o princípio da função social da empresa, de natureza constitucional, por ser corolário do princípio da função social da propriedade, deve não mais ser vislumbrado como norma programática despida de qualquer eficácia, como se proposição ética fosse, mas sim como verdadeiro princípio jurídico que, como tal, tem aplicabilidade imediata, e cujo conteúdo consiste, sobretudo, na percepção da empresa como instrumento não só do alcance dos interesses individuais dos sócios, mas da persecução de objetivos socialmente relevantes, que têm implicações nas relações internas e externas da empresa.
\end{abstract}

A função social da empresa diz respeito às obrigações para com os empregados e consumidores, atividades que dizem respeito igualmente à sociedade, vez que motivam diversas externalidades. Frisa-se, ainda, que os princípios da ordem econômica, previstos no art. $170 \mathrm{CF} /$ $88,{ }^{3}$ estão conectados à função social da empresa, alargando os interesses que devem ser resguardados e atendidos por meio da atividade empresarial (LOPES, 2006, p. 123; 198).

Maria Helena Diniz (1998, p. 613) traz a definição de função social da empresa como: o "exercício pelo administrador da sociedade por ações das atribuições legais e estatutárias para a consecução dos fins e do interesse da companhia, usando do seu poder de modo a atingir a satisfação das exigências do bem comum".

2 Art. 186. A função social é cumprida quando a propriedade rural atende, simultaneamente, segundo critérios e graus de exigência estabelecidos em lei, aos seguintes requisitos: I - aproveitamento racional e adequado; II - utilização adequada dos recursos naturais disponíveis e preservação do meio ambiente; III - observância das disposições que regulam as relações de trabalho; IV - exploração que favoreça o bem-estar dos proprietários e dos trabalhadores. BRASIL. Constituição da República Federal do Brasil de 1988. Brasília: Senado Federal.

3 Art. 170. A ordem econômica, fundada na valorização do trabalho humano e na livre iniciativa, tem por fim assegurar a todos existência digna, conforme os ditames da justiça social, observados os seguintes princípios: I - soberania nacional; II - propriedade privada; III - função social da propriedade; IV - livre concorrência; V - defesa do consumidor; VI - defesa do meio ambiente [...]; VII - redução das desigualdades regionais e sociais; VIII - busca do pleno emprego; IX - tratamento favorecido para as empresas brasileiras de capital nacional de pequeno porte [...]; 
Para se determinar a efetiva função social da empresa, é preciso considerá-la não somente como atividade restrita à busca do lucro e a favor do interesse do empregador, mas também como ente jurídico, cuja funcionalização está cada dia mais representada pelo atendimento de interesses comunitários. Desse entendimento, decorre que a propriedade não atende seu fim social quando sua destinação é conflitante com o interesse coletivo. A empresa está inserida na ordem econômica, como agente organizador da atividade produtiva, gestora das propriedades privadas, consideradas aquelas na fase dinâmica relativa aos bens de produção (CASTRO, 2008, p. 160).

Conforme bem leciona, Vera Helena de Mello Franco (2015, p. 231-232):

[...] a empresa realiza sua função e tem utilidade social quando atua eficientemente
possibilitando melhor locação de recursos e gerando riquezas. Com este teor a utili-
dade social está expressa no resultado da atividade criando postos de trabalho, tribu-
tos, riquezas e, desta forma, contribuindo para o bem estar coletivo. [...] a noção de
justiça social perante a função social da empresa, objeto do nosso tópico, comunga
da ideia de gestão eficiente criando utilidades para o mercado e, destarte, contribu-
indo para o bem estar coletivo.

A função social da empresa alude a um dever social que impõe uma harmonia entre interesse particular e o coletivo, sem, é claro, abduzir de seu escopo lucrativo, inerente à instituição e sem a qual estaria falida.

A função social da empresa determina que a exploração da propriedade não interessa somente ao seu titular e, tampouco, destine-se apenas à busca desenfreada do lucro. Na verdade, determina que os interesses e exercícios decorridos da atividade empresarial devem projetar-se na vida em sociedade, atingindo empregados, fornecedores, fisco e meio ambiente, entre outros. Esta funcionalização ocasiona a superação do caráter individualista, devendo o direito individual do seu titular coexistir com a função social do instituto.

Cristiano Chaves expõe alguns tipos de desdobramentos da função social: no âmbito da aplicação da função da empresa nas atividades internas entre sócios, entre sócios e empregados são: Direito de minoria vencida na mudança estatutária das fundações, art. 68 CC; Participação de empregados nos lucros da empresa. Já na aplicação da função social da empresa nas atividades externas são: Proibição de concorrência desleal Lei antitruste; Proteção do consumidor; Proteção do meio ambiente; meia entrada de estudante (CHAVES, 2010, p. 19-20).

A empresa tem, então, duplo papel, uma vez que serve ao empregador, mas também às necessidades sociais, desempenhando seu papel produtivo em benefício de toda a coletividade (CASTRO, 2008, p. 85). A função social da empresa opera não sobre os fins empresariais (benefícios e lucros), mas sim sobre os meios empregados para alcançá-los.

A função social da empresa tem a intenção de torná-la responsável socialmente, diante das obrigações que lhe atribui a ordem constitucional econômica. Ocorre que essas obrigações não são atingidas quando a empresa se restringe apenas a não prejudicar a sociedade. O cumprimento da função social não diz respeito somente à ausência de prejuízos, mais do que isso, demanda a existência de benefícios sociais.

Os Tribunais têm proferido decisões sobre o dever e a importância de atender a função social da empresa.

APELAÇÃO CÍVEL EM MANDADO DE SEGURANÇA. ADMINISTRATIVO. SOCIEDADE EMPRESÁRIA EM RECUPERAÇÃO JUDICIAL. ATIVIDADE EMPRESARIAL VOLTADA À EXECUÇÃO DE OBRAS PÚBLICAS. LICITAÇÃO. REGRA EDITALÍCIA A QUAL IMPÕE A APRESENTAÇÃO DE CERTIDÃO NEGATIVA DE RECUPERAÇÃO JUDICIAL. PREVISÃO CONTIDA NO ART. 31, INCISO II, DA LEI N. 8.666/1993. PRINCÍPIOS DA FUNÇÃO SOCIAL E DA PRESERVAÇÃO DA EMPRESA (ART. 47 DA LEI N. 11.101/ 
Função social/solidária da empresa nos negócios virtuais

2005). COMPROVAÇÃO DA CAPACIDADE ECONÔMICA-FINANCEIRA QUE PODE SER AFERIDA POR OUTROS ELEMENTOS. RAZOABILIDADE E PROPORCIONALIDADE. EXIGÊNCIA AFASTADA. SENTENÇA REFORMADA. RECURSO PROVIDO. [...]. Os princípios da função social da empresa e da preservação da empresa devem ser aplicados ao caso, uma vez que as sociedades empresariais cumprem importante função social ao gerar empregos, tributos e riqueza, bem como ao contribuir para o desenvolvimento econômico, social e cultural da comunidade em que está inserida

TJ-SC - REEX: 03098919820168240023/ Apelação Cível. Relator: Sérgio Roberto

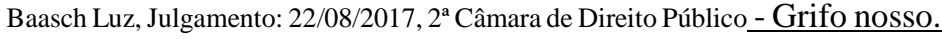

Depara-se com outra decisão, senão vejamos:

RECURSO ORDINÁRIO DO RECLAMANTE. DOENÇA INCURÁVEL. REINTEGRAÇÃO. FUNÇÃO SOCIAL DA EMPRESA. - Em observância ao princípio da função social da propriedade e da busca do pleno emprego (art. 170, III e VIII, $\mathrm{CF} / 88$ ), deve a empresa assumir posição de agente transformador da sociedade, coibindo ações que possam prejudicar, além de seu público, os seus empregados, que também fazem parte da mobilização empresarial.

TRT-19 - RECORD: 1805200200119003 AL 01805.2002.001.19.00-3, Relator: Pedro Inácio, Data de Publicação: 28/11/2007. Grifo nosso.

Função, da maneira como a que se atribui à empresa, corresponde ao "poder de dar ao objeto destino determinado, vinculando-o a certo objetivo" (COMPARATO, 1990, p. 32). A função social da empresa, extraída do princípio da função social da propriedade, redunda em limitação da livre iniciativa. A Carta Constitucional de 1988 consagra, em seu artigo 170, a livre iniciativa privada, entretanto, não se pode valer do pretexto do seu exercício, para acarretar lesão à coletividade, pois a função social da empresa determina que haja uma ponderação da livre iniciativa.

O TRT $1^{\circ}$ Região - RJ manifestou que:

\begin{abstract}
A livre iniciativa é fundamento do Estado Democrático de Direito, e sua coexistência com o valor social do trabalho, no inciso IV, do art. $1^{\circ}$ da Constituição, revela que a atuação da empresa deve ser norteada pela finalidade social, pois o lucro não é um fim em si mesmo ou bem que se possa alcançar abstratamente, uma vez que, como todas as coisas humanas, deve retirar a sua matéria da sociedade, que institui a convivência entre os homens e orienta-se pela realização do progresso e bem estar da coletividade (BRASIL, TRT-1 RJ - RO 00679007620045010302 ).
\end{abstract}

Embora haja inúmeras normas positivadas no sentido de estabelecer uma postura em consonância com a função social da empresa, previstas na Constituição Federal Brasileira de 1988, tais sejam, os artigos $1^{\circ}, 5^{\circ 4}, 170$ e 186, bem como os artigos 421 e 1228 do Código Civil. Esperase que o gestor, no desenvolver de suas atividades empresariais no ambiente eletrônico, opere em conformidade com os princípios da boa-fé objetiva, informação, transparência, confiança e ética que são plenamente aplicáveis como basilares da conduta nas relações de consumo virtual.

A função social originária da ética jurídica demanda dos indivíduos, individualmente vistos como cidadãos, a mudança de comportamento em prol da solidariedade, incorporando, pois, valores instituídos a partir do valor-fonte da dignidade humana, humanísticos princípios éticos formados e instruídos desde os primórdios da civilização humana.

O grande benefício da função social, nesse sentido, é o alto valor reconhecido à existência individual do outro, introduzindo-o de fato numa unidade de cooperação social. Essa cooperação torna a sociedade não o plural do singular homem, mas a pluralidade na sua solidariedade, coesão

4 Art. $5^{\circ}$ inc.XXII, CF/1988. "é garantido o direito de propriedade; XXIII - a propriedade atenderá a sua função social”. 
e unidade internas e externas produzidas para o objetivo comum (CARDOSO, 2010). A solidariedade que aqui se sugere é um direito fundamental que encerra ao indivíduo disposição para algo que lhe é extrínseco.

Com o advento da Constituição Federal Brasileira de 1988, a ideia de função solidária foi impregnada em todo texto constitucional, dedicando, logo no seu art. $3^{\circ}$, os objetivos da República Federativa, que consistem na construção de uma sociedade livre, justa e solidária e na redução das desigualdades sociais. Na atual conjuntura, a Constituição Federal estabelece que os indivíduos se auxiliem mutuamente, porque a construção de uma sociedade livre, justa e solidária é um dever de todos, Estado e cidadãos, ou seja, cada um fazendo sua parte em prol do bem comum.

E é essa a proposta da solidariedade: calibrar o direito e as instituições por ela reguladas à consumação plena do valor da dignidade, pois já não era cedo quando o intérprete da norma jurídica compreendeu que a mesma não poderia continuar a se distanciar dos problemas sociais, isso porque o direito foi instituído para acolher os interesses individuais, coletivos e difusos, de forma compatibilizada, e não o oposto (CARDOSO, 2010, p. 101).

Versando a solidariedade como possível saída para uma sociedade desigual e injusta, mediante a consideração do valor absoluto da dignidade da pessoa humana e seus direitos fundamentais, dos preceitos de justiça distributiva e social (CARDOSO, 2010, p.1).

Nesse sentido, o princípio da solidariedade nasceu como uma cobrança do próprio bem comum, que não pode ser largado de lado ao livre jogo de interesses, nem à vontade dos indivíduos.

O princípio da solidariedade introduziu na ordem jurídica um sistema de ideias baseado no respeito pela dignidade humana, a qual compõe o núcleo essencial dos direitos fundamentais, irradiando seus efeitos para todo o ordenamento jurídico. A dignidade da pessoa humana, e não outro, é o epicentro do projeto solidarista, inscrito justamente nos princípios constitucionais fundamentais (CARDOSO, 2010, p. 25).

Ao atribuir, ao Estado e a todos os membros da sociedade, a responsabilidade de estabelecer uma sociedade solidária, mediante os ditames de justiça distributiva e social, a ordem social democrática agregou um novo valor aos já existentes. Estabelecendo natureza jurídica ao dever de solidariedade, que se tornou passível de exigibilidade (MORAES, 2003, p. 167-190), tanto que a Constituição Federal fixou também, como objetivo, a necessidade de erradicação da pobreza e da marginalização social, entre outras disposições (art. $3^{\circ}$, III, da CF/88).

Não se trata a solidariedade, enfim, de uma obrigação à liberdade individual, mas sim de um valor focado no também valor da dignidade humana, que apenas será alcançado por meio de uma medida de ponderação que oscila entre dois valores, ora propendendo para a liberdade, ora para a solidariedade (CARDOSO, 2010, p. 94).

Afinal, o plano de uma sociedade livre, justa e solidária contradiz a lógica da competição desmedida e do lucro desenfreado, adquirindo, então, um aspecto de cooperação, responsabilidade social, igualdade substancial e justiça distributiva e social.

O princípio da solidariedade, pois, antes de ser princípio, guia o direito em um sentido de valor, despontando que o reconhecimento da dignidade é uma maneira de preservação da vida e da liberdade com igualdade, e nesta lógica, preceitos como justiça, ética e valor da pessoa humana compõem a base fundamental para que o direito se transforme, de fato, em fator de transformação (CARDOSO, 2010, p. 100-101). 
Tal princípio ingressa no sistema jurídico como uma forma de conferir significado ao próximo, correlacionando-se, pois, a um modo de despertar a intencionalidade humana em reconhecer a existência do outro, porque dirige o comportamento à consciência perceptiva do seu ambiente social (MERLEAU-PONTY, 1984, p.12-18).

Sugere ações e persuade condutas, de maneira instintiva, haja vista que os impulsos e as atitudes particulares devem também ser interpretados como uma obrigação, precisamente voltado a tornar mais equânime o ambiente social. O princípio da solidariedade é um meio capaz de reforçar a efetividade do direito social.

A noção de solidariedade é fundamental à própria ordem social, é a ideia de justiça inseparável da ideia de consciência e função social.

A solidariedade está voltada ao conceito de justiça social, na qual o direito é referido à sociedade, procurando construir uma noção de justiça própria, inédita, irredutível às abordagens do direito moderno e do direito clássico (FARIAS, 1998, p. 58).

A justiça social protege a luta contra as regalias, exaltando a dignidade humana no sentido de fazer com que cada um coopere para o desenvolvimento, em todos os seus aspectos, da comunidade, conduzindo o direito positivado à função de compensar a atividade e os interesses dos vários setores (AMARAL, 2000, p. 17-18).

A solidariedade tem por atributo reunir as pessoas no aspecto do bem-comum, dizendo respeito à relação de todas as partes de um todo social (COMPARATO, 2006, p. 577). Sob essa ótica pode ser abarcada como um fato social que dá razão à existência do ser humano no mundo, como benefício ético para que uma pessoa reconheça na outra um valor irrestrito ainda mais amplo do que a justa conduta exigiria, e, ainda, como resultado pragmático para evitar lesão a outrem, a si mesmo e à sociedade (MORAES, 2003, p. 167-190).

O bem comum, elemento mais alto da virtude justiça, representa, pois, uma ordem proporcional de bens em sociedade, de modo que o Direito não tem o fim exclusivo de realizar a coexistência das liberdades individuais, mas sim o fim de conseguir a coexistência e a harmonia do bem de cada um com o bem de todos (REALE, 1998, p. 310).

A solidariedade tornou-se expressiva da evolução do Direito Privado não restringindo a limitação de sua evolução, não circunscrevendo a limitação dos direito privados pelo Direito Público, mas, também, insinuando-se na compreensão do direito de propriedade, das relações contratuais inter subjetiva se, ainda, no direito empresarial, sem esquecer-se da economia social de mercado, hoje imbuída de garantir a todos uma existência digna, segundo os ditames da justiça social (art. 170, caput, da CF/88) (CARDOSO, 2010, p. 102-103).

Há no discurso de solidariedade, uma abordagem que almeja dizer abertamente que não se pode pensar no direito fora dos interesses sociais, pois a partir da constatação de que o direito existe em função da civilização humana, a essência da experiência jurídica deve ser procurada numa lógica de complexidade da trama social, alertando-se neste aspecto que o direito de solidariedade faz parte de uma ação de afirmação do "nós" contra a pressuposição individualista e egoísta do "eu".

Nessa linhagem, a função solidária da empresa agrega a função social, ressalta a essencial ação pró ativa da empresa com aspectos humanos, por meio de aquisições em áreas distintas da meramente lucrativa, a função solidária da empresa propaga exatamente o ligamento dos conceitos de solidariedade ao lado da função social da empresa. 
Pode-se dizer que, cumprir a função social/solidária da empresa nos negócios virtuais também é relacionado ao fornecedor agir com ética, sendo essa considerada por Silveira e Ribeiro (2015) "conteúdo orientador da responsabilidade empresarial e desdobramento da função solidária".

Nas relações de consumo virtual, o consumidor está em situação de vulnerabilidade. As lojas virtuais, para manter sua credibilidade e obterem a estabilidade no comércio eletrônico, devem buscar conquistar a confiança dos clientes, por meio da observância às normas de boa conduta, equilíbrio contratual, colaboração, respeito às leis consumeristas e aos consumidores enquanto pessoas de direito e agentes econômicos. (SILVA; SANTOS, 2013).

Muitas empresas virtuais, visando o cumprimento da função social/solidária nos negócios eletrônicos, implantam em seus sites uma parte destinada para qualificação de vendedor, comprador, produtos e serviços, com a finalidade de conquistar confiança, transparência e segurança nas compras, como forma de evitar induzir o cliente ao erro e gerar inúmeros transtornos.

Nessa mesma visão, a empresa virtual socialmente e solidariamente responsável e preocupada com o futuro do país é aquela que mantém um padrão de qualidade ético e confiável, atendimento ao consumidor com eficiência e clareza, entrega rápida, boa qualidade dos produtos. Bem como não implantar estratégia de obsolescência programada, utilizar sua estrutura virtual para disseminação e conscientização dos consumidores sobre temas relevantes como (preservação do meio ambiente, saúde, não violência, não uso de drogas, oportunidade de emprego, entre outras) e, ainda, compartilhar conhecimentos tecnológicos para contribuir para o desenvolvimento da humanidade.

Um exemplo de empresas que cumprem sua função solidária ao compartilharem seus saberes tecnológicos são as que vendem Impressoras 3D utilizadas para fabricação de próteses, algumas delas disponibilizam gratuitamente em sua plataforma digital sobre projetos de próteses, possibilitando qualquer pessoa que tem aptidão e vontade de fabricar próteses para seu uso ou para doações. Dentre elas, deparamo-nos com a empresa e movimento E-nabling the future (ou E-nable), que expõe a seguinte manifestação: "A ideia é colaborativa e tem como objetivo distribuir conhecimento para a produção de próteses infantis de baixo custo, a partir da tecnologia de impressão 3D" (PUPO, 2014). Essa iniciativa traz a reabilitação motora e psicológica e, acima de tudo, a dignidade das pessoas que utilizam as próteses.

Existem algumas lojas virtuais que cumprem sua função solidária, conforme citadas a seguir: a loja virtual (e-commerce) fundada por Lou de Olivier, onde tudo é vendido a preços bem acessíveis e grande parte dos valores arrecadados é doada a projetos filantrópicos e animais abandonados. A fundadora faz inúmeras publicações científicas de relevância mundial, dispensa direitos autorais de todos os e-books, por esse motivo os preços podem ser bem populares - a partir de R\$ 3,00 (DINO, 2017).

Existe, ainda, a Eco Choice, uma loja virtual de produtos Sustentáveis como roupas, sapatos, bolsas, materiais de decoração entre outros, todos feitos com materiais recicláveis, a loja tem escopo de proteção ao meio ambiente e disseminar o consumo consciente (NEGRI, 2010).

O princípio da solidariedade uniu o Estado e entes privados. Ao decidir a socialidade como uma intenção estatal, a Constituição de 1988 preferiu por conectar os cidadãos em uma sociedade onde todos têm o direito e o dever de cooperar para o bem do próximo.

As empresas tanto no meio tradicional, virtual ou mista, estão aderindo à função solidária, implantando planos de sustentabilidade, seja por real preocupação ao bem estar coletivo ou simplesmente pela onda do Marketing de sustentabilidade, visto que, segundo a pesquisa realizada pela "EcGlobal, 98\% dos consumidores consideram importante que as companhias se preocupem 
com o meio ambiente, [...] e 47\% pagariam até 5\% a mais em produtos sustentáveis" (MUNDO DO MARKETING, 2017).

Um exemplo de crescimento do faturamento após implantar ideais de sustentabilidade é a empresa Unilever, que também utiliza a internet a seu favor. Lançou, em 2010, o Plano de Sustentabilidade que tem como visão geral aumentar os negócios, diminuir o impacto ambiental e aumentar o impacto positivo na sociedade. As marcas da empresa com propósitos sustentáveis aumentaram mais de $60 \%$ do faturamento total da companhia. O Presidente da Unilever no Brasil reforça que "O crescimento das marcas com propósito comprova que inserir a sustentabilidade no coração do negócio não só é a melhor decisão, como se mostra o único caminho viável para as empresas que visam o longo prazo" (MIAMOTO, 2017).

Assim, a sociedade deve ser um ambiente de diálogo, cooperação entre pessoas, com individualidade, mas também visando um destino comum. Nesse aspecto, a Constituição Federal determina que os indivíduos se ajudem entre si, porque a construção de uma sociedade livre, justa e solidária, cabe a todos. Podemos perceber que o texto constitucional expressa uma vontade, uma ordem que deve ter suas ações para o atingimento de um estado ideal, uma finalidade a ser alcançada exclusivamente para sociedade, ou seja, o bem comum (CUNHA, 2014).

A solidariedade é a expressão mais profunda da sociabilidade que caracteriza a pessoa humana, visto que a Constituição Federal de 1988 exige ajuda mútua, para uma sociedade livre, justa e solidária.

Enfim, as empresas virtuais também são responsáveis pela edificação do futuro da humanidade. Mesmo com a estrutura virtual, a empresa tem que cumprir a função social/solidária nos negócios virtuais, agindo com a verdade, respeito, boa-fé, ética, segurança e não visar lucro a qualquer preço. Deve visar o bem estar coletivo para garantir uma sociedade digna e justa para as presentes e futuras gerações.

\section{Conclusão}

A evolução tecnológica espalha seus efeitos nas mais diversas áreas e setores, notadamente, é um grande e eficiente instrumento no campo empresarial, possibilitando mais celeridade, facilidade, diversidade e rentabilidade nos negócios. A Internet criou uma revolução nos meios de comunicação global, alterou as possibilidades de se transacionar comercialmente em todo o mundo. A internet se tornou um verdadeiro diferencial no atual mercado competitivo e com ela surge o modelo de comércio eletrônico.

Com a finalidade de acompanhar o acelerado desenvolvimento tecnológico e expandir os negócios através do meio eletrônico, as empresas convencionais estão se adaptando e criando estabelecimentos virtuais para atender de forma eficiente e rápida os diversos perfis de consumidores da atualidade, suprindo suas necessidades, expectativas e desejos.

As empresas virtuais favorecem a competitividade nos negócios e, consequentemente, o desenvolvimento econômico, mas em razão da natureza do próprio negócio acarreta vantagens e desvantagens para empresa e para o consumidor.

Pontuam-se algumas das principais vantagens dos negócios na internet para os consumidores, tais como a quebra de obstáculo de tempo e distância, formas de pagamento diferenciadas, preços competitivos, facilidade de comparar produtos, preços e marcas. Além, do conforto de fazer as compras onde, quando e como quiser, ainda tem a tranquilidade para comparar, refletir, tirar dúvidas, entrega em domicílio, entre outras. Para os empreendedores os benefícios são as 
novas chances de ampliação dos negócios, obtenção de lucro, maior alcance do público alvo, estoque baixo, estrutura de funcionário enxuta, marketing virtual eficiente e mais barato, etc.

Nesse comércio virtual há também algumas desvantagens, como ataque de vírus, falha na segurança de dados, carência de atendimento personalizado, comunicação inadequada e confusa, dificuldade na troca, endividamento, problemas logísticos referentes a falhas no prazo de entrega ou entrega de produtos defeituosos, entre outros. Algumas das desvantagens estão ligadas a desvios da função social, por exemplo, a propaganda enganosa, negócios que impliquem desvio ético ou econômico com intuito de prejudicar terceiros.

A empresa tem sua importância no contexto social, visto que ocupa papel relevante nas sociedades capitalistas, uma vez que toda a economia é fruto de processo produtivo de natureza empresarial. A função social da empresa é um desdobramento da discussão sobre a solidariedade social, visto que a propriedade deixa de ser instrumento de satisfação apenas de seu titular e passa a ser analisada dentro do contexto social.

A função social da empresa alude a um dever social que impõe uma harmonia entre interesse particular e o coletivo, sem, é claro, abduzir de seu escopo lucrativo inerente à instituição e sem a qual estaria falida. A função social da empresa opera não sobre os fins empresariais (benefícios e lucros), mas sim sobre os meios empregados para alcançá-los.

Com o advento da Constituição de 1988, a ideia de função solidária foi impregnada no texto constitucional, dedicando, logo no art. $3^{\circ}$, os objetivos da República. Na atual conjuntura, o princípio da solidariedade uniu o Estado e entes privados, estabeleceu que os indivíduos, se auxiliem mutuamente, porque a construção de uma sociedade livre, justa e solidária e a redução das desigualdades sociais, é um dever de todos, cada um fazendo sua parte em prol do bem comum.

A função social estendida à atividade econômica passa a exigir da empresa liberdade de iniciativa, livre concorrência em conformidade com os valores fundamentais da dignidade da pessoa humana e da solidariedade. Não mais se admite uma atividade empresarial, sendo ela virtual ou não, desvinculada da função social, nem distante dos objetivos fundamentais previstos na Constituição Federal de 1988.

A empresa virtual social e solidariamente responsável e preocupada com o futuro do país é aquela que mantém um padrão de qualidade ético e confiável, atendimento ao consumidor com eficiência, respeito e clareza, não induzir o cliente a erro, utilizar a estrutura virtual para disseminação e conscientização dos consumidores sobre temas relevantes. Ainda, a oferta de produtos e serviços de boa qualidade, não implantar estratégia de obsolescência programada, decisões pautadas em fins sustentáveis, compartilhar conhecimentos tecnológicos para contribuir para o desenvolvimento da humanidade.

Enfim, mesmo que as empresas tenham estrutura virtual, não as eximem do cumprimento da função social/solidária em seus negócios, as empresas são essenciais para o desenvolvimento econômico do país e não podem ser indiferentes à realidade cultural, educacional, ambiental, social em que estão inseridas, devendo ter uma postura ativa, cooperando valorosamente para a concretização dos direitos e objetivos constitucionais. As empresas virtuais devem ter uma estratégia de valorização da dignidade humana e justiça social, pois elas também são responsáveis por fomentar o desenvolvimento social do país, para as presentes e futuras gerações. 


\section{REFERÊNCIAS}

ALBERTIN, A. Comércio eletrônico: modelo, aspectos e contribuições de sua aplicação. 6. ed. São Paulo: Atlas, 2012.

ALINE, Naiane. UOL. Negócios virtuais crescem 24\% mesmo em tempos de crise. 2015. Disponível em: < http://atarde.uol. com.br/empregos/noticias/1685225-negocios-virtuais-crescem-24-mesmo-em-tempos-de-crise>. Acesso em: 08 jun. 2017.

AMARAL, Francisco. Direito Civil: Introdução. 3. ed. Rio de Janeiro: Renovar, 2000.

BAUMAN, Zygmunt. Vida líquida. Tradução Carlos Alberto Medeiros. Rio de Janeiro: Jorge Zahar, 2007.

BECK, Ulrich. Sociedade de risco: rumo a uma outra modernidade. 2. ed. São Paulo: 34, 2011.

BRASIL. Constituição da República Federal do Brasil de 1988. Brasília: Senado Federal.

BRASIL. Lei ${ }^{\circ}$ 10406, de 10 de janeiro de 2002. Institui o Código Civil. Disponível em: <http:// www.planalto.gov.br/ccivil_03/leis/2002/L10406.htm>. Acesso em: 02 out. 2017.

BRASIL. TJ- SC. REEX: 03098919820168240023 Capital 0309891-98.2016.8.24.0023, Relator: Sérgio Roberto Baasch Luz, Data de Julgamento: 22/08/2017, Segunda Câmara de Direito Público) - Apelação Cível. Disponível em: <https://tj-sc.jusbrasil.com.br/>. Acesso em: 18 nov. 2017.

BRASIL. TJ-DF - ACJ: DF 0115476-63.2013.8.07.0001, Relator: ARNALDO CORRÊA SILVA, Data de Julgamento: 17/03/2015, $2^{\text {a }}$ Turma Recursal dos Juizados Especiais do Distrito Federal, Data de Publicação: Publicado no DJE: 06/04/2015. Pág.: 214. Disponível em: <https:// tj-df.jusbrasil.com.br/>. Acesso em: 10 nov. 2017.

BRASIL. TRT-1 RJ - RO 00679007620045010302. Rel. Rogerio Lucas Martins. Publicação: 16/07/2015. Disponível em: <https://trt-1.jusbrasil.com.br/jurisprudencia/209966393/recursoordinario-ro-679007620045010302 -rj>. Acesso em: 28 maio 2017.

BRASIL. TRT-19 -AL 01805.2002.001.19.00-3. Rel. Pedro Inácio, Publ. 28/11/2007. Disponível em: <https://trt-19.jusbrasil.com.br/jurisprudencia/8860303/recurso-ordinario-record1805200200119003-al-0180520020011900-3-trt-19\#!>. Acesso em: 28 maio 2017.

BRUNO, Vinicius. SPC BRASIL. Pesquisas-compras por impulso. 2015. Disponível em: <https://www.spcbrasil.org.br/pesquisas/ pesquisas/filtro/tema/compras-por-impulso>. Acesso em: 13 maio 2017.

CARDOSO, Alenilton da Silva. Princípio da Solidariedade: o paradigma ético do direito contemporâneo. São Paulo: Juarez de Oliveira, 2010.

CASTRO, Mariângela Conceição Vicente Bergamini de. O princípio da função social da propriedade: empresa. Dissertação (Mestrado em Direito) - UNIMAR, Marília - SP, 2008.

CHAVES, Cristiano. Direito Civil/Função social da empresa. 2010. Disponível em: <http:// www.academia.edu/6479608/_D._Civil_-_Apostila_de_Cristiano_Chaves>. Acesso em: 15 maio 2017.

COELHO, Fábio Ulhoa. Curso de Direito Comercial. 6. ed. São Paulo: Saraiva. 2006.

COMPARATO, Fábio Konder. Direito empresarial: estudos e pareceres. São Paulo: Saraiva, 1990. 
COMPARATO, Fábio Konder. Ética: Direito, Moral e Religião no Mundo Moderno. São Paulo: Companhia das Letras, 2006.

COSTA, Rodrigo Fernandes da. Internet e Negócios O que mudou? Universidade de São Paulo. Instituto de Ciências Matemáticas e de Computação. 2010. Disponível em: <http:// wiki.icmc.usp.br/images/0/0d/SCC0207 - Graca_Grupo16Artigo.pdf>. Acesso em: 28 abr. 2017.

CUNHA, Guilherme Oliveira. Função social da sociedade empresária: a importância da sanção para o cumprimento da função social. Centro Universitário Newton Paiva. Letras Jurídicas. 2014. Disponível em: <http://npa.newtonpaiva.br/letrasjuridicas/?p=146.>. Acesso em: 14 jun. 2017.

DINIZ, Eduardo Henrique. Comércio Eletrônico: Fazendo Negócios por meio por meio da Internet. RAC: Revista de Administração Contemporânea, Rio de Janeiro, v. 3, n. 1, p. 71-86, jan./ abr. 1999.Disponível em: <http://www.scielo.br/pdf/rac/v3n1/v3n1a05>. Acesso em: 27 abr. 2017.

DINIZ, Maria Helena. Dicionário Jurídico. São Paulo: Saraiva. vs. 2-4, 1998.

DINO. Portal Terra. Loja virtual solidária, mais uma iniciativa de Lou de Olivier. Pub. 12 maio. 2017. Disponível em:<https://www.terra.com.br/noticias/dino/loja-virtual-solidaria-mais-umainiciativa-de-lou-de-olivier,0cc2f428df295c384e7da8c801ba9439lgbpw9h9.html >. Acesso em: 10 maio 2017.

FARIAS, José Fernando de Castro. A origem do Princípio da Solidariedade. Rio de Janeiro: Renovar, 1998.

FRANCO, Vera Helena de Mello. Função social e procedimento recuperacional: a função social sob novo enfoque Social. Direito \& Justiça: revista de direito da PUCRGS, v. 41, n. 2, p. 225 237, jul./dez. 2015. Disponível em: <http://revistaseletronicas.pucrs.br/ojs/index.php/fadir/article/view/21436>. Acesso em: 15 nov. 2017.

LOPES, Ana Frazão de Azevedo. Empresa e propriedade: função social e abuso do poder econômico. São Paulo: Quartier Latin, 2006.

MARKER, Graciela. Informaticahoy. Crear la estratégia adecuada para una tienda virtual. 2017. Disponível em: <http://www.informatica-hoy.com.ar/tiendas-virtuales/Crear-la-estrategia-adecuada-para-una-tienda-virtual.php>. Acesso em: 08 jun. 2017.

MATIAS, João Luis Nogueira; MENDES, Davi Guimarães. A exclusão de sócio incapaz na sociedade limitada: análise à luz do princípio da função social da empresa. Revista Jurídica da UNI7, Fortaleza, v. 13, n. 2, p. 13-23, dez. 2016. Disponível em: <http://www.uni7setembro.edu.br/periodicos/index.php/revistajuridica/article/view/59>. Acesso em: 02 out. 2017.

MENEZES, Hilton Alexandre Gil. Um modelo de comércio eletrônico: estratégias de negócio-a-consumidor em pequenas empresas. Dissertação (mestrado em Ciência da Computação). Universidade Federal de Santa Catarina. Florianópolis, 2002. Disponível em: <https://repositorio.ufsc.br/ bitstream/handle/123456789/82329/ 267015.pdf?sequence=1>. Acesso em: 28 abr. 2017.

MERLEAU-PONTY, Maurice. O Visível e o Invisível. 2. ed. São Paulo: Perspectiva, 1984.

MIAMOTO, Isa. SEGS. Marcas sustentáveis impulsionam crescimento da Unilever. Publicado em: 5 jun. 2017. Disponível em: <http://www.segs.com.br/demais/67154-marcas-sustentaveis-impulsionam-crescimento-da-unilever.html>. Acesso em: 11 jun. 2017. 
MORAES, Maria Celina Bodin de. Princípio da Solidariedade. Rio de Janeiro: Lúmen Júris, 2003.

MUNDO DO MARKETING. Comportamento do Consumidor em relação à sustentabilidade. Disponível em: <https://www.mundodomarketing. com.br/inteligencia/pesquisas/110/comportamento-do-consumidor-em-relacao-a-sustentabilidade.html>. Acesso em: 11 jun. 2017.

NEGRI, Guilherme Augusti. Eco Choice - Loja virtual de produtos Sustentáveis. Coletivo Verde, 2010. Disponível em: <http://www.coletivoverde.com.br/eco-choice-loja-virtual-de-produtos-sustentaveis/>. Acesso em: 10 jun. 2017.

NETO, Guilherme. Redes Sociais são responsáveis por $62 \%$ do tráfego na Internet. Publ. 04/ 09/2009, Mundo do Marketing. Disponível em: <https://www.mundodomarketing.com.br/reportagens/comportamento-do-consumidor/11077/redes-sociais-sao-responsaveis-por-62-do-trafego-na-internet-brasileira.html>.Acesso em: 01 out. 2017.

OLIVEIRA, Cláudia Dias de. Modelo de negócios inovadores, em plataformas virtuais e orientado para sustentabilidade: uma abordagem do design como processo. Dissertação (mestrado). Universidade do Estado de Minas Gerais, Escola de Design, 2014.

PAYÃO, Jordana Viana; SANTIAGO, Mariana Ribeiro. A função social e solidária da empresa no âmbito das relações de trabalho. Nomos: Revista da Pós-Graduação em Direito da UFC, Fortaleza, v. 36, n. 2, p. 243, 260, jul./dez. 2016. Disponível em: <http://www.periodicos.ufc.br/ index.php/nomos/article/ viewFile/2555/4563>. Acesso em: 05 maio 2017.

PEREIRA, Susana Carla Farias; MAIA, Marta de Campos; SERIO, Luiz Carlos Di. Modelos de negócios na economia digital. 2002. Disponível em: <http://gvpesquisa.fgv.br/sites/gvpesquisa.fgv.br/files/arquivos/marta_campos_maia_modelos_de_negocios_na_economia_digital.pdf>. Acesso em: 27 ago. 2017.

PUPO, André. Projeto colaborativo oferece próteses infantis de baixo custo inspiradas em superheróis. 2014. Disponível em: <http://www.hypeness.com.br/2014/10/brasileiro-cria-protese-infantil-do-ben-10-com-ajuda-do-e-nabling/>. Acesso em: 11 jun. 2017

REALE, Miguel. Fundamentos do Direito. 3. ed. São Paulo: Revista dos Tribunais, 1998.

RIDOFRANZ. Brasil é o $4^{\mathbf{0}}$ país em número de usuários de internet. Exame. Por Agência Brasil. 2017. Disponível em: < https://exame.abril.com.br/tecnologia/brasil-e-o-4o-pais-em-numero-de-usuarios-de-internet/>. Acesso em: 18 nov. 2017.

SALOMÃO FILHO, Calixto. Função social do contrato: primeiras anotações. Revista de Direito Mercantil, São Paulo, Malheiros, v. 42, n. 132, p. 7-24, out./dez. 2003.

SALVADOR, Maurício. Como abrir uma loja virtual de sucesso. Rio de Janeiro: Gramma, 2010.

SANTIAGO, Mariana Ribeiro; MEDEIROS, Elisângela Aparecida De. Função social e solidária da empresa: impactos na liberdade econômica versus benefícios no desenvolvimento nacional. Revista Jurídica, Curitiba, v. 02, n. 47, p. 99-122, 2017.

SILVA, Michael César; SANTOS, Wellington Fonseca dos. O direito do consumidor nas relações de consumo virtuais. Revista Eletrônica de Direito do Centro Universitário Newton Paiva, n. 21, p. 39-55, out. 2013. Disponível em: <http://npa.newtonpaiva.br/direito/?p=1294>. Acesso em: 05 maio 2017. 
SILVEIRA, Vladimir Oliveira; RIBEIRO, Elenice Baleeiro Nascimento. Ética: conteúdo da responsabilidade corporativa e desdobramento da função solidária da empresa. Revista Argumentum, Marília/SP, v. 16, p. 37-54, jan./dez. 2015.

SZTAJN, Rachel. Teoria Jurídica da Empresa: Atividade empresária e mercados. São Paulo: Atlas, 2004.

TURBAN, Efraim. Comércio Eletrônico: Estratégia e Gestão. Tradução Arlete Simille Marques. São Paulo: Prentice Hall, 2004.

YOSHIDA, Lêda Pena. Uma análise das vantagens e desvantagens dos portais de compras coletivas sob a ótica do empreendedor: Um Estudo MultiCasos em MPE's do Setor de Serviços. Dissertação (mestrado em administração) - Faculdade Campo Limpo Paulista - SP: FACCAMP, 2015. Disponível em: <http://www.faccamp.br/new/arq/pdf/mestrado/Documentos/producao_discente/LedaPenaYoshida.pdf>. Acesso em: 04 dez. 2017.

Recebido em: 06 out. 2017.

Aceito em: 06 dez. 2017. 